\title{
Analysis of overhead cost behavior: case study on decision-making approach
}

\author{
Petr Novák \\ Tomas Bata University in Zlin \\ Czech Republic \\ pnovak@fame.utb.cz. \\ Ján Dvorský \\ Tomas Bata University in Zlin \\ Caech Republic \\ j1dvorsky@fame.utb.cz.
}

\section{Boris Popesko}

Tomas Bata University in Zlin

Czech Republic

popesko@fame.utb.cr.

\section{Jiř́ Strouhal}

Škoda Auto University

Czech Republic

jiri.stroubal@savs.cz.

Abstract. Cost management is one of the most significant issues in company performance and company financial management which any enterprise has to solve as in the periods of declines of sales revenues, as well as during their growth. In this study we designed and tested several regression models that could be suitable for cost behavior prediction and subsequent decision-making based on these predictions. We used multiple linear regression models with a point estimate and with interval estimate of the model parameters. Comparison of regression models of cost behavior and their reliability was carried out due to the quality of the data collected for the case of basic and adjusted data. The overheads were divided into several groups of relevant costs and their dependences were examined on different factors other than only the production volume using the correlation matrix. From the results of the transformed model we believe that asymmetric cost behavior is affected by asymmetric behavior of the chosen factors. As the final one was intended the model representing the change in costs in time shifting about one-month period. This model can be used for examining costs in time shift by a short period (e.g., months) and thus it is possible to prove 
cost asymmetric behavior called "sticky costs". We used the model adjusted in accordance with Anderson et al. (2003). and we kept the model clearly transformed and assembled so that there remained only those variables that had a statistically significant effect on the dependent variable. The limitations of these models were also defined. Finally, graphical analyses of deviations were performed to find similarities in cost through cost centres and through the examined periods.

Keywords: cost management, cost behavior, regression analysis, asymmetric cost behavior, decision-making process, overhead costs, sticky costs.

JEL Classification: D70

\section{INTRODUCTION}

Cost management is one of the most significant issues for any company and at any stage of its development. Moreover, this topic is much more relevant after the world financial crisis which started in 2007/2008. Before this crisis, companies used to spend money even they did not know why, they hired staff they did not need, and they did not track costs in detail, some companies did not even have controlling department . During the crisis, however, many companies have found it necessary to change this attitude. Now every company tries to reduce its costs across the whole firm, from administration to production. But cost management does not mean only cost reduction. Cost management is a process that should lead to better use of costs and higher production volumes and revenues. Without exaggeration, we can say that cost management could be considered as one of the core activities in economic practice of industrial companies. Since in recent decades the structure of economy, manufacturing, operations and customer requirements have all changed, so the view on cost management had to be also changed.

The structure of enterprise activities is changing due to increasing customer demands for product modification, more intensive R\&D and innovation activities. To this is also related a significant change in cost structure, which resulted in rising share of overhead costs up to about 35-40\% (Novák, \& Popesko, 2014).

Costing methods, techniques and systems represent the key instruments for measuring business performance. Especially cost classification in cost analysis, i.e. costs are placed into defined categories according to their given characteristics. It is important to note that traditional and standard appraisal of cost behavior, measured purely by the volume of production or sales, would not seem up to the job of meeting the current needs of (manufacturing) enterprises.

Managers are interested in estimating previous cost behavior patterns, since this information can accelerate more precise cost forecasts concerning planning and decision-making (Pichetkun, \& Panmanee, 2012). Important information may also be gained by investigating cost dependence and their behavior on different factors, from which prognostic models can be derived useful for cost estimates. In fact, ignorance of cost behavior and cost dependence may lead to errors in judgment, from minor to major in scope. This is why there exists an increased pressure on the research of cost variability (particularly of overheads) and how to project these findings into costing systems or decision-making process, resulting in determining the appropriate price of a product.

The main goal of this article is to examine and analyze indirect overhead costs and their behavior from the perspective of potential dependencies on defined factors of the concrete industrial company. In connection with the main objective a partial goal is to propose a predictive model that would reflect the 
observed dependencies and thus help managers in making adequate decisions. Another partial objective is to set up procedures that can be applied in further case studies conducted within the project titled "Variability of cost groups and its projection in the costing systems of manufacturing enterprises," so that it could help generalize the predictive model of behavior and dependence of the overhead costs.

\section{LITERATURE REVIEW}

Knowing how costs change with activity output changes is an essential part of planning, controlling, and decision making. (Hansen, 2009) Ways to proceed with the assessment of costs and their analysis are numerous. Financial accounting uses a method of cost classification in financial statements. Such classification sorts natural types of costs by the form of the input consumed. The classification based on the financial statements is not enough today. But many of the companies are not willing to change their old costing methods and systems (Sharman, 2003) The owners of these companies defend of changing the old system because of another costs which could be arising from the new system implementation, also some employees of accounting departments are not willing to learn new methods and even do not accept the new system. However, in managerial accounting, the term cost is applied in numerous ways. Okunbor (2013) defines the term "cost" as an economic resource that has a value. Cost should be used to generate the profit. Cost can be mentioned also as the total expenses of the company that have to be paid to make the production or provide the services. For example Drury (2012) as another from many authors states the main division of costs and titles them as direct and indirect costs. Direct costs primarily comprise direct materials and labor, representing those easily and accurately identified with a particular cost object. Therefore, indirect costs cannot be determined specifically and exclusively with a given cost object. (Drury, 2012; Hansen \& Mowen, 2015).

Issues related to an increasing proportion of overhead costs and any subsequent impact on cost management were defined by Nimocs et al. (2005). Indeed, Hansen et al. (2009) further comment that cost assignment is a key process within a cost accounting system. Studies have shown that up to $80 \%$ of companies continue to use (or have switched back to) traditional product-costing methods, despite the fact that many accountants within these companies express dissatisfaction with relying on the outputs of such cost accounting systems for decision-making purposes (Sharman, 2003). Knowledge of cost behavior is very important, especially for decision-making. As Okunbor (2013) stated, cost behaviour is associated with learning how costs change when there is a change in an organization's level of activity. It is important to understand the cost behaviour in company so the company's management is able to make the right decision in the sphere of planning and managing the costs For each decision taken, the management of a company requires estimates of costs and revenues at different levels of activity for alternative courses of action. Meanwhile the behavior of the costs and any subsequent decision depends on the cost driver. For instance, Popesko goes even further and states that criticism of standard traditional cost models is also evident in other areas of cost management, e.g. in budgeting. Such opinions resulted in new methods being introduced, such as activity-based budgeting and beyond budgeting. (Popesko, 2016)

A traditional model of cost behavior separates costs into fixed and variable components. But in practise it is not so easy. As Anderson (2009) said no cost is completely fixed or completely variable. The latter are modified in proportion with changes that occur in performance volume, but fixed costs remain unaltered as volume changes within a relevant range. (Hilton et al., 2008) Indeed, the narrative can be about purely variable costs, as well as completely fixed, semi-variable and semi-fixed ones (Drury, 2012). Bozkurt et al. (2014) stated that there are three main types of expenses in business costs: first material and equipment 
costs, direct labour costs and general production costs. There exist also main cost centres and subsidiary cost centres. Bozkurt et al. (2014) furthermore explained the main cost centres as the places where manufacturing takes place and actual labour costs are realized. For example, in furniture industry there are the places where raw material cutting, banding and perforation are realized and they are the main production centres. The subsidiary production centres are the places where technical support activities are realized in order to make the production continuously. The cost calculation methods are required for the calculation of all costs which occur in these cost centres. Therefore, today the traditional and modern methods are worked to be used together.

The above mentioned issue is further confirmed by Banker and Byzalov (2014). They stated, that understanding of cost behavior is a key part in cost accounting. They add to this, that better understanding of cost behavior has useful implications not only for cost accounting but also for financial accounting topics such as earnings forecast and earnings management. The standard concept of cost behavior and their assessment as variable and fixed costs is mentioned by almost every author. It is also mentioned generally, that fixed and variable costs are short-term concepts, but "in the long run, all costs are variable" in the sense that all resources are subject to managerial discretion over the long term (Noreen \& Soderstrom, 1994; Hansen et al., 2009 etc.). The importance of fixed and variable costs area also mention authors Slavik and Bednar (2014) in their work focusing on business models, specifically in Gross Margin model and Operating model.

Costs are caused by resources. Some resources, such as indirect skilled labor, are costly to adjust in the short term so are predisposed to generating fixed costs. (Hansen et al., 2009; Banker \& Byzalov, 2014; etc) Banker and Byzalov (2014) also ask whether firms that face greater demand uncertainty tend to possess a less rigid cost structure with lower fixed costs and higher variable costs, or a more rigid cost structure with higher fixed and lower variable costs. Their results, which are based on less formal analysis of the issue, are contrary to widely held opinions. And it is important to understand the cost behavior in company so the company's management is able to make the right decision in the sphere of planning and managing the costs. In connection with the managerial decision making, there exists another differentiation of cost groups, which are known as controllable and non-controllable costs. As Oluwagbemiga et al. (2014) mentioned a controllable cost is any cost which is under the direct influence of a responsible manager for a given time period. It is suggested that the costs and revenue must be related to individual who is responsible for their incurrence. This system is known as the "responsibility accounting".

The traditional approach of cost behavior postulates that the costs of activities change proportionately with the volume of activity and that the considered variable costs are directly altered in adherence with alteration in the activity driver. In contrast, cost accounting and management operate also with asymmetric costs. (e.g. Anderson et al., 2003; Anderson et al., 2009; Via \& Perego, 2013). Asymmetric costs behave asymmetrically to activity increase and decrease so the response to decline in cost is either less or greater than a response to the rising costs of an operation.

The cost behavior issue is deeply investigated also by authors Banker and Byzalov. They argue that with more uncertain demand, unusually high realizations of demand become more likely. Evidence strongly supports their hypothesis that firms facing higher demand uncertainty have a more rigid short-run cost structure with higher fixed and lower variable costs. (Banker, Byzalov, \& Plehn-Dujowich, 2014) Such cost behavior is referred to as rigid or fast-moving (Abu-Serdaneh, 2014). The importance of this issue is also the subject of a study by Japanese authors (Pichetkun et al., 2012), who utilized regression analysis for the behavior of costs and their explanation of the causes of sticky costs. And as Weiss (2010) emphasizes, results indicate that businesses with stickier cost behavior have less correct analysts' earnings forecasts than 
businesses with less sticky cost behavior. The issue of sticky cost is engaged in a very detailed for example by Balakrishnan et al. in their publications (e.g. Balakrishnan \& Gruca, 2008). Another view of the sticky costs issue introduces e.g. Uy (2011), which incidentally refers to the authors, which exclude the existence of sticky cost. According to him, literature notes that the cost may not be linear and proportional to the level of activity.

But as a first main study of this issue of asymmetric costs (they called them Sticky cost), was presented by Anderson et al. (2003 and 2004), whose study introduced the concept of cost stickiness, explained their choice of measurement that lacked large datasets on activity levels and total costs. They found out that SG\&A (selling, general and administrative) costs of 7629 firms increase on average at a rate of $0.55 \%$ per $1 \%$ increase in sales but decrease only $0.35 \%$ per $1 \%$ decrease in sales. They included the value of fixed assets and the number of employees as the additional drivers of SG\&A costs and found sticky cost behaviour with respect to both of these drivers. As there can be delays in adjusting costs for changes in activity, they estimated a specification of the model that includes delayed revenue change and delayed interaction variables for revenue decreasing periods. The results of this estimation show that stickiness partially reverses over time.

While Anderson and Lanen (2009) warned that changes in sales do not express exogenous repressors; this is because sales are not only dependent on production volume, but also prices that are set by management. Furthermore, Anderson and Lanen (2009) emphasize that classifying costs is subject to managerial choice, and that selling, general, and administrative costs (hereafter "SG\&A") represent merely $30 \%$ of total cost. Consequently, these create measurement problems when investigating cost behavior. Anderson et al. presented an empirical study measured cost stickiness using the sticky cost regression model that enables measurement of the SG\&A response to contemporaneous changes in sales revenue and discriminates between periods when revenue increase and revenue decreases. (Anderson et al. 2003) Anderson and Lanen (2009) also found evidence of sticky cost behavior in their own sample, they found no consistent mode of cost behavior when they explored the premise of sticky cost behavior for other types of costs that are also subject to managers' consideration including: advertising, labour wages, research development, property, plant and equipment. They found sticky behavior for other costs and they found evidence that costs are significantly "anti-sticky." It is confirmed again that these costs increase faster when activity increases than they decrease when activity decreases. These findings do not lead to reject the theory of cost management based on adjustment cost, because this result is acceptable. The documented cost behaviour is not revealing in relation to cost management without further structure.

Something comparable was also presented by Abu-Serdaneh (2014) in his study, when he discovered anti-sticky cost behavior for the costs of goods sold (CGS) and selling expenses, while the cost behavior for SG\&A and administration costs was found to be symmetrical. The CGS model shows an increased degree of stickiness for companies with high asset intensity, whereas a lesser degree of stickiness was discerned for free cash flow.

Anderson et al. (2003) indicated the sticky cost as today's phenomenon. Research by Yasukata and Kajiwara (2011) revealed that the difference in cost stickiness even larger when managers are more optimistic about the future sales even when sales decline; hence the reason to keep slack resources for future use. When analyzing the level of individual stickiness between SG\&A costs and the costs of goods sold (hereafter "COGS"), they found that SG\&A costs were stickier than those for COGS. Another survey was performed by Brüggen and Zehnder (2014). They found out and confirmed, that when applying textbook methods that are based on the traditional model of cost behavior, e.g. flexible budgeting or cost-plus pricing, it is necessary to consider that costs do not necessarily behave mechanistically, but might be sticky. As evidenced by the 
analysis in this study, cost behavior is sensitive to incentives provided to the manager. (Brüggen \& Zehnder, 2014)

Banker, Byzalov, Ciftci \& Mashruwala (2014) redefined the standard theory of sticky costs. Their study supported Anderson, Banker and Janakiraman fundamental insight that asymmetric cost behaviour reflects deliberate resource commitment decisions by managers stated in 2003. They showed that this intuition gives rise to a complex fundamental model of cost asymmetry that mixes two different processes: cost stickiness conditional on a prior sales increase, and cost anti-stickiness - the opposite of the standard predictions conditional on a prior sales decrease. These predictions show the impact of managers' expectations for future sales on their actual resource commitments, together with the general structure of the best decisions with resource adjustment costs. Their theory proposed a two-period model of asymmetric cost behaviour. The results they provided are strong across various cost groups, including all major components of operating costs and including physical number of employees. Their results also indicated that the standard view of cost stickiness can be refined substantially by implementing the insight from the two-period model.

Another factors that watched Chen, Gores and Nasev (2013) as the cause of sticky costs was excessive confidence of managers. The authors assumed that too confident manager have a greater overestimation of future demand and therefore managers are the ones who usually do not reduce costs when demand decreases. Research has been subjected to more than 14,000 enterprises in years 1992-2011.

It turned out that the study's authors assumption was correct and sticky costs were indeed more frequent in businesses where managers was too overconfident. According to the study the formation of these undesirable costs did not spring from lack of overview of managers, but it was due the good managers' intentions to meet shareholder expectations. Unfortunately, no cost reduction in a situation of demand declining resulted in enterprises into emergence of sticky costs. (Chen et al., 2013)

Differences in sticky cost between different countries were examined in the study of the authors Calleja, Steliarosa and Thomas (2006). They used the sample of American, English, French and German enterprises to detect differences between various countries. Based on the analysis used they found that the German and French companies are much stickier than the costs of American and English enterprises. This result is attributed to the differences in the system of accountability of senior management towards the owners and other stakeholders in the company and the differences in the other factor-attention of managers. They found out, that American and British companies are under higher pressure from external control and requirements to maximize profits for shareholders. Managers therefore have to pay more attention to the correctness of their decisions connected with the issue of cost management. In France and German enterprises, the managers are not subject to such pressure from shareholders in their decisions and therefore the rate of sticky costs in these countries is higher. (Calleja et al., 2006)

Another survey was presented by UY (2014), when he stated, that competitive advantage is not only measured by the revenues and profits but also by how firms operate efficiently (costs).

Directly contrary to the studies mentioned above, Via and Peregro (2014) presented a paper that investigated whether cost stickiness occurred in small and medium sized companies. Their findings show that cost stickiness only emerges for the total cost of labor and not for SG\&A costs, the cost of goods sold and operating costs. Stickiness of operating costs is only detected in a sample of listed companies.

These and many other studies clearly demonstrate the need for exploration, making the comparisons and verification of this issue with other countries, also as it pertains to manufacturing enterprises in the Czech Republic. 


\section{THE FORMULATION OF THE RESEARCH PROBLEM}

This paper presents results of behavior of overhead costs and their variability in relation with selected of factors in manufacturing company. The results of this paper were used to solving of the above mentioned grant project. The company is possible include to classification in accordance EU-NACE 22.11Manufacture of rubber tires and tubes; retreading and rebuilding of rubber tires. The company is engaged in the production of tires for different sectors of the national economy. Major customer is the agricultural sector (agricultural machinery). Production of tires is very similar from the view of manufacturing process. The differences in the production of tires are only in quantity of the material used and of the length of the vulcanization. Unit of measure may be a number piece or weight of the products. It's an advantage for the company.

For research of our project were selected period of two years. We used company data from year 2014 to 2015 (monthly overheads and development). The data which we had received from the company can be divided into variable costs, total overhead costs (TOC), modified total overhead cost (TOCm), overhead costs influenceable (IOC), modified overhead cost influenceable (IOCm), overhead costs uninfluenceable (UOC), modified overhead costs uninfluenceable (UOCm). The following section will focus the attention on a comparison of statistics signification of linear regression models between dependent variables (TOC, UOC, IOC) and modified dependent variables (TOCm, UOCm, IOCm).

The dependence on various factors was examined by thus divided costs. As the default for the study were chosen five factors as independent variable among which was the assumption they can influence the overhead cost occurrence and their movement. The independent variable (factors) were:
a) The number of orders entering the manufacturing process $(\mathrm{NoO})$
b) The number of batches of vulcanized tires (NoB)
c) Production in pieces of tires (Qpcs)
d) Production in $\mathrm{kg}(\mathrm{Qkg})$
e) Total production time (TPT)

\subsection{Basic descriptive statistics dependent and independent variables}

Statistical analysis was performed with software (Statgraphics Centurion XVI.). Hypotheses were formulated about the effect of independent variables (factors) on the dependent variables (groups of overhead cost). Statistical hypothesis testing was performed at the 0.05 level of significance. We obtained analytical data for the period years 2014 and 2015 (24 - months observations). These data were analysed as six separated time series (dependent variables). Calculated characteristics of the descriptive statistics dependent variables are in Table 1.

Overheads acts as the dependent variable in the model \# 1, and these are „Total overheads“ TOC (Mean= $48281200 \mathrm{CZK}$ per month, SD=6 $365200 \mathrm{CZK}$ ) and in the model \# 1a, and these are „Modified Total overheads" TOCm (Mean=48 003200 CZK per month, SD=6 397920 CZK).

In model \#2 these are „Uninfluenced overheads” UOC (Mean=6 $481690 \mathrm{CZK}$ per month, SD=647 $769 \mathrm{CZK}$ ) and „Modified uninfluenced overheads” UOCm (Mean=6 $378440 \mathrm{CZK}$ per month, SD=518 $584 \mathrm{CZK}$ ). Comparison in these costs is expressed in figure 1. And in model \#3 there are expressed influenced overheads IOC (Mean = $3257520 \mathrm{CZK}$ per month with SD = $831645 \mathrm{CZK}$ ) and „Modified influenced overheads" IOCm (Mean=3 $056030 \mathrm{CZK}$ per month, SD=572 411CZK). Comparison you can see in Fig. 2. 
Basic characteristics of descriptive statistics independent variables

\begin{tabular}{|c|c|c|c|c|c|c|}
\hline \multirow[b]{2}{*}{ Basic characteristics } & \multicolumn{6}{|c|}{ Overhead (Dependence variables) } \\
\hline & $\begin{array}{l}\text { TOC } \\
\text { (CZK) }\end{array}$ & $\begin{array}{l}\text { TOC }_{\mathrm{m}} \\
(\mathrm{CZK})\end{array}$ & $\begin{array}{l}\text { IOC } \\
(\mathrm{CZK})\end{array}$ & $\begin{array}{l}\mathrm{IOC}_{\mathrm{m}} \\
(\mathrm{CZK})\end{array}$ & $\begin{array}{l}\text { UOC } \\
(\mathrm{CZK})\end{array}$ & $\begin{array}{l}\mathrm{UOC}_{\mathrm{m}} \\
(\mathrm{CZK})\end{array}$ \\
\hline Mean & 48281200 & 48003200 & 3257520 & 3056030 & 6481690 & 6378440 \\
\hline $\begin{array}{c}\text { Standard deviation } \\
\text { (SD) }\end{array}$ & 6365200 & 6397920 & 831645 & 572411 & 647769 & 518584 \\
\hline Lower Quartile (LQ) & 44220100 & 44170900 & 2752000 & 2655290 & 6070490 & 6027880 \\
\hline Upper Quartile (UQ) & 49223600 & 47728900 & 3734670 & 3301690 & 6876270 & 6808600 \\
\hline
\end{tabular}

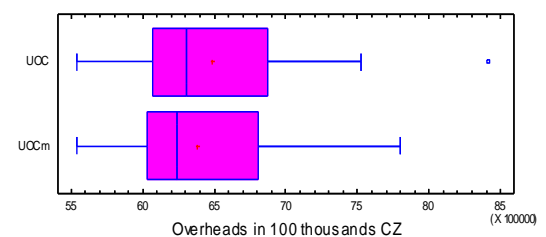

Figure 1. Box-and-Whisker plots of UOC and $\mathrm{UOC}_{\mathrm{m}}$ overheads

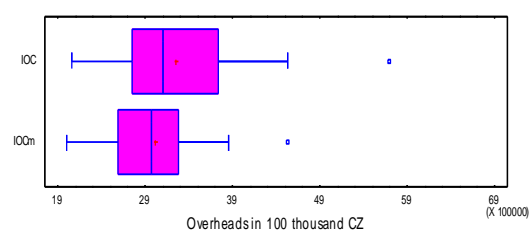

Figure 2. Box-and-Whisker plots of IOC and IOCm overheads

In Figure 1 and Figure 2 you can see that in the time series of the UOC, IOC, IOCm is minimum one extreme value of overheads and that in the time series of the UOCm is not extreme value of overheads. The independent variables were represented by $\mathrm{NoO}$, NoB, Qpcs, Qkg, TPT (independence variables). Calculated characteristics of the factors are in Table 2.

Basic characteristics of descriptive statistics independent variables

\begin{tabular}{|c|c|c|c|c|c|}
\hline \multirow{2}{*}{ Basic characteristics } & \multicolumn{5}{|c|}{ Factors (Independence variables) } \\
\cline { 2 - 6 } & NoO (pcs) & NoB (pcs) & Qpcs (pcs) & Qkg (kg) & TPT (min) \\
\hline Mean & 3889.6 & 173.2 & 26133.5 & 3029390 & 3714720 \\
\hline $\begin{array}{c}\text { Standard deviation } \\
\text { (SD) }\end{array}$ & 801.5 & 28.1 & 5886.4 & 3670835 & 808527 \\
\hline $\begin{array}{c}\text { Lower Quartile } \\
\text { (LQ) }\end{array}$ & 3786.5 & 155.5 & 23199.5 & 2738790 & 3377060 \\
\hline $\begin{array}{c}\text { Upper Quartile } \\
\text { (UQ) }\end{array}$ & 4491.5 & 197.5 & 29656.5 & 3462420 & 4195530 \\
\hline
\end{tabular}

The explanatory variables are represented by continuous variables of $\mathrm{NoO}$ in period (Mean=3 890 per month, $\mathrm{SD}=801.5), \mathrm{NoB}$ (Mean=173.2, SD=28.1), Qpcs (Mean=26 133.5 per month, $\mathrm{SD}=5$ 886.4), Qkg (Mean=3 029390 per month, $\mathrm{SD}=3670$ 835) and TPT (Mean=3 714723 per month, $\mathrm{SD}=808$ 527). The 
difference between the LQ and the UQ can be interpreted as that $50 \%$ of all collected data is in the group, for example. The production in $\mathrm{kg}(\mathrm{Qkg})$ were in the interval from $27 \mathrm{~kg}$ to $3462420 \mathrm{~kg}$ per month. If variability increases in the interval between the lower and upper quartile, the group is inhomogeneous.

For time series UOC and UOCm we also analysed transformed ABJ model because their regression models had statistical significant parameters. We used transformed ABJ model (Anderson's etc.) because regression models better investigate asymmetry in cost responses. Basic characteristics of descriptive statistics represented Mean, Standard deviation (SD), Lower Quartile (LQ), Upper Quartile (UQ). Results of basic characteristic shows table 1 and table 2 . The Regression analysis with autoregressive error was used to analyse the effect of covariates and Durbin-Watson is examined to test the autocorrelation.

\subsection{Testing independent Variables to meet the Assumptions of Linear Regression Models}

The linearity assumption was tested by scatter plots and was met if no nonlinear patterns were observed in the relationship between the dependent and independent variables. The normality assumption was tested in two ways: firstly, by creating a normal probability plot for every independent variable; secondly, by a statistical test measuring two characteristics of every variable (kurtosis and skewness) and then statistical zvalue for each characteristic. These statistical test were conducted according to Hair (2010), the critical values for the significant level of 0.05 was \pm 1.96 . The graphical test of linearity showed the fulfilment of this assumption, i.e. there were found linear relations between selected dependent variable and dependence variables (factors).

Table 3

Skewness, kurtosis and $z$ - value of independent variables for each model with dependent variable

\begin{tabular}{|c|c|c|c|c|c|}
\hline \multirow{2}{*}{$\begin{array}{c}\text { Basic characteristics } \\
\text { z- test }\end{array}$} & \multicolumn{5}{|c|}{ Factors (Independence variables) } \\
\cline { 2 - 6 } & NoO (pcs) & NoB (pcs) & Qpcs (pcs) & Qkg (kg) & TPT (min) \\
\hline Skewness & -1.0204 & 0.4274 & -1.0258 & -1.1020 & -1.1996 \\
\hline z- value & -2.0409 & 0.8548 & -2.0516 & 1.2041 & -1.3992 \\
\hline Kurtosis & 0.1778 & -0.6350 & 0.0861 & 0.3259 & 0.5846 \\
\hline z-value & -3.4184 & 2.8437 & 4.3471 & 1.8955 & 0.4687 \\
\hline
\end{tabular}

The results in Tab. 3 showed that the variable number of batches of vulcanized tires does not follow the normal distribution in kurtosis; the variables number of orders entering the manufacturing process and production in pieces of tires does not follow the normal distribution neither in skewness nor in kurtosis. Only the variables total production time (min.) and production in $\mathrm{kg}$ follow the normal distribution in skewness and in kurtosis too. In the next step we calculated the correlation matrix for each dependent variable (TOC, UOC, IOC, TOCm, UOCm, IOCm) and independent variables (factors: NoO, NoB, Qpcs, Qkg, TPT). Based on the results in tab. 3 and results of relevant correlation matrices between the dependent variable and the factors that:

- the first independent variable to be included in the model with dependent variable TOC, TOCm is total production time in min (Pearson coefficient correlation (R) between TOC and TPT is 0.7543 ; $\mathrm{R}$ between TOCm and TPT is 0.7598 ); 
- the first and second independent variable to be included in the model with dependent variable UOC, UOCm are total production time in min and production in $\mathrm{kg}$ ( $\mathrm{R}$ between UOC and TPT is 0.84214 ; R between UOCm and TPT is 0.81242); R between UOC and Qkg is 0.6487; R between UOCm is 0.6532);

- neither one independent variable was not included in the model with overhead costs influenceable and in the model with modified overhead costs influenceable too.

Homoscedasticity was tested by a graphical test as well. Firstly, there was performed a regression analysis of every pair of independent and dependent variable. Secondly, the regression analysis output was used to create a scatter plot. The homoscedasticity assumption is met if points are distributed homogenously throughout the scatter plot. The results testing of homoscedasticity (Darvin Watson test) did not show any violation of this assumption for any independent variable.

\subsection{Model estimation, testing and validation}

The create each model between dependent variable and independent variables and its determinant there was used method of multiple regression analysis. Other independent variables were then included according to their partial correlations and t- values. Independent variables were included in the model if their calculated $\mathrm{t}$ - value $\geq 2.0686$ ( 23 degrees of freedom, significance level at 0.05 ). The results were calculated for each model in the column t-Statistic. When the p- value is greater than level of significance 0.05 after was rejected statistical significance independent variable in the model. The model validation was realized by coefficient of determine (R2) and $\mathrm{p}$-value. When the $\mathrm{p}$ - value is greater than level of significance 0.10 after was rejected statistical significance regression model. The multicollinearity assumption was tested by Variance Influence factor (VIF). The multicollinearity assumption was calculated only for significant regression models (UOC, UOCm).

\subsection{Main research objectives}

Create a model of the relationship between groups of overhead costs and the above mentioned factors. At this stage, this can be considered as a basic outcome of partial research activity. There were used the statistical method of regression analysis with autoregressive errors.

A further object is to carry out the investigation on the basis of the findings whether there are affected the costs behavior arising from changes in previous periods. The aim here is to create a model for the dependencies time lag of one period (month).

The last aim is to create a prediction model of overheads development that can be utilized in a managerial decision making. In the model, the dependent variable is represented by uninfluenceable overheads and the effect of continuous variables (individual defined factors) on overhead costs is modeled in a given month.

\section{RESULTS OF TESTING OF MULTIPLE REGRESSION MODELS}

To meet the main objectives have been formulated research questions. For their verification it was necessary to design appropriate models. To verify the research questions were designed multiple regression models. Assumptions to perform multiple regression models were:

There exists a dependence of the overhead costs behavior on selected defined factors.

We assume in accordance with the theoretical starting points that the overhead costs behavior is primarily dependent on the factors unrelated to volume of production. Especially the factors like "Number 
of orders" and "Number of batches" can have a significant impact on the growth or decline in overhead costs (whether influenceable or uninfluenceable).

The results of the comparison of models with basic data and models with adjusted data - Statistical significance models with adjusted data is better than the statistical significance of models with basic data.

Third research assumption is that overhead costs may vary depending on changes in factors examined, and these result out of the changes to the previous periods (i.e. the period $\mathrm{t}-1, \mathrm{t}-2$, etc.).

In summary, four regression models were developed, one of which has been transformed. The following relationship shows the formula for the calculation of six basic models.

$$
Y_{t}=\beta_{0}+\beta_{1}{ }^{*} \mathrm{NoO}{ }_{t}+\beta_{2}{ }^{*} \mathrm{NoB} B_{t}+\beta_{3}^{*} Q \operatorname{Qpcs}+\beta_{4}{ }^{*} Q k g_{t}+\beta_{5}{ }^{*} T P T_{t}+\varepsilon_{t}
$$

The results comparison TOC and TOCm is possible interpreted as:

- that a statistically significant factor that effects on total overheads is TPT (see Table 4),

- that a statistically significant factors are not in regression model of modified total overheads (see Table 5).

Model \#1 with dependent variable total overhead costs (TOC), Parameter Estimates. DurbinWatson $=0.9753 ; \mathrm{p}=0.173 ; \mathrm{R}^{2}=0.34$

\begin{tabular}{|l|l|l|l|l|}
\hline \multicolumn{2}{|l|}{ Parameter Estimates } & Coefficient estimate & t- Statistic & P - value \\
\hline Intercept & $\boldsymbol{\beta 0}$ & 42602681 & 3.9599 & 0.0009 \\
\hline Noo & $\boldsymbol{\beta 1}$ & -2660.93 & -0.5979 & 0.5574 \\
\hline Nob & $\boldsymbol{\beta 2}$ & -6721.06 & -0.0753 & 0.9408 \\
\hline Qpcs & $\boldsymbol{\beta 3}$ & 1614.2 & 0.6257 & 0.5394 \\
\hline Qkg & $\boldsymbol{\beta 4}$ & 3.5344 & 0.1228 & 0.0936 \\
\hline TPT & $\boldsymbol{\beta 5}$ & $\mathbf{- 9 . 6 1 0 5}$ & $\mathbf{- 0 . 7 1 8 2}$ & $\mathbf{0 . 0 4 7 8}$ \\
\hline
\end{tabular}

Table 5

Model\#1a with dependent variable modified total overhead costs (TOCm), Parameter Estimates. DurbinWatson $=2.154 ; \mathrm{p}=0.2386 ; \mathrm{R}^{2}=0.14$

\begin{tabular}{|l|l|l|l|l|}
\hline \multicolumn{2}{|l|}{ Parameter Estimates } & Coefficient estimate & t- Statistic & P - value \\
\hline Intercept & $\boldsymbol{\beta 0}$ & 40789389 & 3.7295 & 0.0015 \\
\hline Noo & $\boldsymbol{\beta 1}$ & -2346.98 & -0.5187 & 0.6103 \\
\hline Nob & $\boldsymbol{\beta 2}$ & 12296.64 & 0.1355 & 0.8937 \\
\hline Qpcs & $\boldsymbol{\beta 3}$ & 1540.84 & 0.5875 & 0.5642 \\
\hline Qkg & $\boldsymbol{\beta 4}$ & 2.81 & 0.0961 & 0.0925 \\
\hline TPT & $\boldsymbol{\beta 5}$ & -9.31 & -0.6842 & 0.5026 \\
\hline
\end{tabular}

Out of the detailed results of model \# 1 can be seen that a statistically significant effect on Total overheads factor has the factor of TPT $(\mathrm{p}=0.0478)$ when these overheads Total decrease of 9.61 with 
increasing production time (better utilization of production capacity with less frequency of manufacturing intermediate operations). Out of the detailed results of model \# 1a can be seen, that a statistically significant effect on Total overheads factor has not any factor.

The results comparison shows that a statistically significant effect on uninfluenced overheads have factors Qkg together with TPT and that a statistically significant effect on modified overheads have factors Qkg together with TPT (see Table 6 and table 7).

Table 6

Model \#2 with dependent variable uninfluenceable overhead costs (UOC), Parameter Estimates. DurbinWatson=1.368; $\mathrm{p}=0.0951 ; \mathrm{R}^{2}=0.45$

\begin{tabular}{|c|c|c|c|c|}
\hline \multicolumn{2}{|c|}{ Parameter Estimates } & $\begin{array}{c}\text { Coefficient estimate } \\
\text { (CE) }\end{array}$ & t- Statistic & P - value \\
\hline Intercept & $\beta 0$ & 5824940 & 6.5165 & 0.0000 \\
\hline Noo & $\beta 1$ & -481.8658 & -1.3031 & 0.2090 \\
\hline Nob & $\beta 2$ & 13403.341 & 1.8069 & 0.0875 \\
\hline Qpcs & $\beta 3$ & -280.6313 & -1.3092 & 0.2069 \\
\hline Qkg & $\beta 4$ & $\mathbf{7 . 3 8 8 4}$ & $\mathbf{3 . 0 8 9 3}$ & $\mathbf{0 . 0 0 6 3}$ \\
\hline TPT & $\beta 5$ & $\mathbf{- 3 . 9 9 4 5}$ & $\mathbf{- 3 . 5 9 2 7}$ & $\mathbf{0 . 0 0 2 1}$ \\
\hline
\end{tabular}

Table 7

Model \#2a with dependent variable modified uninfluenceable overhead costs (UOCm), Parameter Estimates. Durbin-Watson=1.251; $\mathrm{p}=0.0843 ; \mathrm{R}^{2}=0.52$

\begin{tabular}{|c|c|c|c|c|}
\hline \multicolumn{2}{|c|}{ Parameter Estimates } & $\begin{array}{c}\text { Coefficient estimate } \\
\text { (CE) }\end{array}$ & t- Statistic & P - value \\
\hline Intercept & $\beta 0$ & 6164264 & 9.2609 & 0.0000 \\
\hline Noo & $\beta 1$ & -394.4225 & -1.4324 & 0.0692 \\
\hline Nob & $\beta 2$ & 7153.5786 & 1.2951 & 0.2117 \\
\hline Qpcs & $\beta 3$ & -171.1707 & -1.0724 & 0.2977 \\
\hline Qkg & $\beta 4$ & $\mathbf{5 . 8 2 0 4}$ & $\mathbf{3 . 2 6 8 2}$ & $\mathbf{0 . 0 0 4 3}$ \\
\hline TPT & $\beta 5$ & $\mathbf{- 3 . 4 0 5 2}$ & $\mathbf{- 4 . 1 1 2 8}$ & $\mathbf{0 . 0 0 0 7}$ \\
\hline
\end{tabular}

Estimates of regression coefficients show:

- that uninfluenced overheads fluctuate, and it upwards (CE $=7.3884, \mathrm{p}$ - value $=0.0063$ ) with increasing manufactured kilograms $(\mathrm{kg})$ and downwards $(\mathrm{CE}=-3.9945, \mathrm{p}-$ value $=0.0021)$ with TPT (in minutes),

- that modified uninfluenced overheads fluctuate, and it upwards (CE $=5.8204, \mathrm{p}=0.0043)$ with increasing manufactured kilograms $(\mathrm{kg})$ and downwards $(\mathrm{CE}=-3.4052, \mathrm{p}=0.0007)$ with TPT (in minutes).

The results comparison between the model \#2 and model \#2a are detailed in Table 6 and Table 7. Factors as Qkg and TPT are significant (Qkg: p- value $>0.01$ and TPT $>$ p - value $>0.005)$. Theas means that independence factor (Qkg and TPT) are major factor of uninfluenceable overhead costs (UOC) on their prediction. Further work is based on identification of the possible predictors that should have 
significant impact on predicted variables. The result of VIF test on the multicollinearity assumption of $\mathrm{UOCm}$ are $\operatorname{VIF}(\mathrm{NoO})=5.2010 ; \operatorname{VIF}(\mathrm{Nob})=6.2241 ; \mathrm{VIF}(\mathrm{Qpcs})=5.6474 ; \operatorname{VIF}(\mathrm{Qkg})=1.8053 ; \operatorname{VIF}(\mathrm{TPT})$ $=0.8410$.

The results show that due to the Variances Influence Factor (VIF) was found significant (strong) the effect of multicollinearity by independent variables NoO, Nob, Qpcs. The results of VIF test of factors (Qkg, TPT) show that was not found significant effect of multicollinearity (Hair, 2010).

The final function of regression model of development UOCm arising out the table 6 is as follows:

$$
\begin{gathered}
\text { UOCm }=6164264-394.42 * \mathrm{NoO}+.7154 * \mathrm{NoB}- \\
-171.17 * \text { Qpcs }+5.82 * Q \mathrm{~kg}-3.41 * \mathrm{TPT}
\end{gathered}
$$

None of the other factors was proved the statistically significant effect on the IOC and also on the modified influenceable overhead cost (IOCm) because statistical significances factors were upper than level of significance 0.05 .

The results comparison model \#with IOC and model \#3a with IOCm are in Table 8 and Table 9.

Table 8

Model \#3 with dependent variable influenceable overhead costs (IOC), Parameter Estimates. Durbin-

Watson $=2.155 ; \mathrm{p}=0.2378 ; \mathrm{R}^{2}=0.28$

\begin{tabular}{|c|c|c|c|c|}
\hline \multicolumn{2}{|c|}{ Parameter Estimates } & Coefficient estimate & t- Statistic & P - value \\
\hline Intercept & $\beta 0$ & 4733085 & 3.6390 & 0.0019 \\
\hline Noo & $\beta 1$ & -544.61 & -1.0122 & 0.3249 \\
\hline Nob & $\beta 2$ & -14642.59 & -1.3566 & 0.1917 \\
\hline Qpcs & $\beta 3$ & 77.9017 & 0.2498 & 0.8056 \\
\hline Qkg & $\beta 4$ & 1.3995 & 0.4021 & 0.6923 \\
\hline TPT & $\beta 5$ & -0.8337 & -0.5153 & 0.6126 \\
\hline
\end{tabular}

Table 9

Model\#3a with dependent variable modified influenceable overhead costs (IOCm), Parameter Estimates.

Durbin-Watson $=2.171 ; \mathrm{p}=0.2237 ; \mathrm{R}^{2}=0.21$

\begin{tabular}{|c|c|c|c|c|}
\hline \multicolumn{2}{|c|}{ Parameter Estimates } & Coefficient estimate & t- Statistic & P - value \\
\hline Intercept & $\beta 0$ & 2727920 & 2.4937 & 0.0226 \\
\hline Noo & $\beta 1$ & -165.6 & -0.3659 & 0.7187 \\
\hline Nob & $\beta 2$ & 5551.7 & 0.6116 & 0.5485 \\
\hline Qpcs & $\beta 3$ & -36.5352 & -0.1393 & 0.8908 \\
\hline Qkg & $\beta 4$ & 1.0251 & 0.3503 & 0.7302 \\
\hline TPT & $\beta 5$ & -0.5879 & -0.4321 & 0.6708 \\
\hline
\end{tabular}

As last two models were calculated the models representing the costs change by one month. In our case, we are applied the shift of only one month due to the lower range of data observations (months). Regression analysis transformed according to ABJ of transformed models were assembled so that identified 
factors, which were statistically significant on the groups of overheads costs (dependence variable). The assembled model \# 4 and model \# 4a looks like the following:

$$
\log \left(\frac{\mathrm{UOC}_{t-1}}{\mathrm{UOC}_{\mathrm{t}}}\right)=\beta_{0}+\beta_{1} * \log \left(\frac{\mathrm{Qkg}_{\mathrm{t}-1}}{\mathrm{Qkg}_{\mathrm{t}}}\right)+\beta_{2} * \log \left(\frac{\mathrm{TPT}_{\mathrm{t}-1}}{\mathrm{TPT}_{\mathrm{t}}}\right)+\varepsilon
$$

Estimates regression coefficients (with used transformed model) and reliability of the models as a whole are shown in table 10 and table 11.

Transformed Model \#4 for dependent variable uninfluenceable overhead costs (UOC), Durbin Watson=1.672; $\mathrm{p}=0.252 ; \mathrm{R}^{2}=0.23$

\begin{tabular}{|c|c|c|c|c|}
\hline \multicolumn{2}{|c|}{ Parameter Estimates } & Coefficient estimate & t- Statistic & P - value \\
\hline Intercept & $\boldsymbol{\beta 0}$ & 0.002 & 0.2415 & 0.8116 \\
\hline Delta Qkg & $\boldsymbol{\beta} 1$ & 1.1201 & 2.0915 & 0.0494 \\
\hline Delta TPT & $\boldsymbol{\beta 2}$ & -1.1806 & -2.2177 & 0.0383 \\
\hline
\end{tabular}

Table 11

Transformed Model \#4a for dependent variable modified uninfluenceable overhead costs (UOCm),

Durbin Watson $=1.778 ; \mathrm{p}=0.337 ; \mathrm{R}^{2}=0.30$

\begin{tabular}{|c|c|c|c|c|}
\hline \multicolumn{2}{|c|}{ Parameter Estimates } & Coefficient estimate & t- Statistic & P - value \\
\hline Intercept & $\boldsymbol{\beta 0}$ & 0.0007 & 0.1035 & 0.9186 \\
\hline Delta Qkg & $\boldsymbol{\beta 1}$ & 1.0029 & 2.4711 & 0.0226 \\
\hline Delta TPT & $\boldsymbol{\beta 2}$ & -1.0655 & -2.6413 & 0.0157 \\
\hline
\end{tabular}

The results of our models \# 4 and \#4a, as well as of the results of the models \#2 and \#2a shows that the UOC and UOCm are significantly influenced by the production volume in kg (Model \#4: Qkg; 1.12 times, $\mathrm{p}=0.0494$, Model \#4a: Qkg 1.00 time, $\mathrm{p}=0.0226$ ) and by the minutes of production (Model \#4: TPT; -1.18 times, $\mathrm{p}=0.0383$, Model \#4a: TPT, -1.0655, $\mathrm{p}=0.0157$ ). The linear regression models (model $\# 4$; model\#4a) have statistically significant coefficients ( $\mathrm{p}$ - value $<0.05$ ). Final model can then be modified as follows (3)

$$
\begin{aligned}
& \log \left(\frac{U O C_{t-1}}{U O C_{t}}\right)=\log (1)+\log \left(\frac{Q k g_{t-1}}{Q k g_{t}}\right)^{1.12}++\log \left(\frac{T P T_{t-1}}{T P T_{t}}\right)^{-1.18}+\varepsilon \\
& \log \left(\frac{U O C_{t-1}}{U O C_{t}}\right)=\log \left(1 *\left(\frac{Q k g_{t-1}}{Q k g_{t}}\right)^{1.12} *\left(\frac{T P T_{t}}{T P T_{t-1}}\right)^{1.18}\right)+\varepsilon \\
& \log \left(\frac{U O C_{t-1}}{U O C_{t}}\right)=\log \frac{\frac{Q k g_{t-1}^{1.12}}{T P T_{t-1}^{1.18}}}{\frac{Q k g_{t}^{1.12}}{T P T_{t}^{1.18}}}+\varepsilon
\end{aligned}
$$


from which arising after adjustment (relations (4) and (5)) that if we want to stabilize fluctuations in overhead costs, we have to stabilize proportion between kilograms and minutes of production).

\section{CONCLUSION}

The proposed methodology for evaluating of different types of costs and their deeper analysis using multiple regression models with linear function as well as transformation of statistic model by Anderson (2003) can bring to the company new ways of evaluating and interpreting the independent drivers (factors) for managerial decisions. Based on this information and knowledge manager could be able to understand the proposed model interrelationships and dependencies of costs and their determinants.

And even though we cannot demonstrate in their application the significance of factors such as e.g. the number of orders. And another factor - number of batches is significant only closer to the confidence level $\alpha=10 \%$. Nevertheless, these models can be seen as the way to a deeper exploration of behavior overheads dependence. The following conclusions aroused of these models application. We managed to prove that there exists a correlation of overhead costs behavior on some selected factors (drivers), which confirmed the assumption "A". Somewhat surprisingly, it appears that the most significant difference was demonstrated in the overhead cost group which can be described as uninfluenceable (e.g. Depreciation of machinery; costs related to machinery tools; tools, etc.). There has been demonstrated the dependence on the factors of production character, such as on the volume of production in $\mathrm{kg}$, and also on the production time quantity (in minutes) of manufacturing process. Assumption "B" about possible depending on factors unrelated to production volumes was refuted by this finding.

This may be caused due to very close link in the character of production, when the production can be designated almost homogeneous, since it is mainly one modified product whose difficulty of operations in the manufacturing process remains in each modification almost the same. These products differ mainly in the amount of material used (which represent the variable costs), the length of preparation and final vulcanization phase. There exists also a weaker dependence by a factor number of batches, where, however, the significance of this factor only approached to a formal significance $(p=0.1314)$ and there cannot be therefore attributed greater importance to this factor. The results of model investigation revealed that the factors produced volume of production in $\mathrm{kg}$ and total time of the manufacturing process cannot be fundamentally separated from each other.

Thus, if we want optimize and stabilize overheads at approximately constant value within the managerial decision tasks so as to avoid large fluctuations of overheads, it is necessary to optimize the ratio of the total time of the manufacturing process with the amount of production produced in $\mathrm{kg}$. And all this is valid under the conditions of keeping a stable level of rationality in production and in the productivity. Another aim will be to monitor this phenomenon and to ensure the optimal balance between these two factors. The transformed model was designed following the ABJ regression models (Anderson et al, 2003) that showed a statistically significant correlation of the two factors - production in $\mathrm{kg}$ and total production in minutes. By using of this model (model \# 4, Table 9; Model \# 4a, Table 10) we showed that the variability of overhead costs (concretely UOC and modified UOCm) are affected by the volume of these factors in the previous reporting period (month). Based on the aforementioned results, we confirmed the premise "C". The regression model with a linear function of the models (UOC - model \# 2 and UOCm - model \# 2) can be modified by regression variable of $1.12^{*} \mathrm{Qkgt}-1-1,1806^{*} \mathrm{TPTt}-1$ for the model of dependent variable UOC and also by regression variable of $1.0029 *$ Qkgt-1-1,0655*TPTt-1 for model of UOCm 
dependent variable. These changes are caused from the past can and could be explored and explained in more consecutive prior periods.

It is apparent from the comparison of regression models with dependent variables UOC, IOC, TOC and modified variables UOCm, IOCm, TOCm that the modification of overhead costs increases the reliability of the regression model (UOC a UOCm) for statistically significant parameters (Qkg a TPT) for statistically significant parameters (QKG and TPT), using a coefficient of determination (R2) and also the p-value. On the contrary, in models of IOC and IOCm was reduced reliability regression models (inverse correlation), where there are no statistically significant factors on the basis of R2 and p-value. Due to the lower number of the reference periods (only 24 months) it is expected that the results achieved in next periods will better determine the reliability and interpretation of the dependent factors on different types of costs using regression models and their transformation by Anderson etc. For the sake of completeness, we mention the fact that for all modifications of costs we approached individually and on the basis of consultations of the research team with representatives of enterprise and that responsible economic department.

For completeness, it is necessary to mention the limitations of these models. There must be taken into into consideration several aspects in their compilation. One of the first we must mention the quality of the input data. In the business practice we can unfortunately meet number of irregularities in accounting very often that may affect the input data, and thus also the final results.

It may be, e.g. improperly charged costs in one period (month, quarter), which then the entity rectifies in the following season. This may cause artificially created fluctuations in costs, which do not display their actual developments and may diverge with the reported values of selected factors in the related periods. The higher fluctuations in overheads, the higher volatility it can also be in the results of the regression model and It may reduce their predictive value. In this context, it is necessary to mention the seasonality in both production as well as in the birth of overhead costs that would be described as extraordinary or gusty (it could be e.g. exceptional purchase of machinery, equipment, the extraordinary fines, fees, crash personal cost-13th or 14th month pay etc.). In this case, it is necessary to make adjustments of the data consisting eg. of the dissolution or distribution of these extraordinary costs among all months of the year (as they relate to the whole economic year, although they are charged only in one month). Another option would be to compensate for the statistical time row etc. As more noticeable error appears to be the extent and the length of the period studied (observation). The greater the extent of the sample we have, the better could be these multiple regression models for future periods.

In conclusion we can sump up this problematics, that these models can show to the management new insight on the overheads behavior. And also due to the fact that, particularly in the manufacturing sector, the issue is often solved very marginally, e.g. only through budgets. Furthermore, it opens up the possibility of extending the use of standard simplified cost function (based on classical concepts of fixed and variable costs), which is used almost unchanged for several decades.

\section{ACKNOWLEDGEMENT}

This paper is one of the research outputs of the project GA 14-21654P/P403 "Variability of Cost Groups and Its Projection in the Costing Systems of Manufacturing Enterprises" registered at the Czech Science Foundation. 


\section{REFERENCES}

Abu-Serdaneh, J. (2014). The asymmetrical behavior of cost: evidence from Jordan. International Business Research, 7(8), 113.

Anderson, M. C., Banker, R. D., \& Janakiraman, S. N. (2003). Are selling, general, and administrative costs "sticky"? Journal of Accounting Research, 41(1), 47-63.

Anderson, M., Banker, R., Chen, L., \& Janakiraman, S. (2004). Sticky costs at service firms. Working Paper, University of Texas at Dallas.

Anderson, S. W., \& Lanen, W. N. (2009). Understanding cost management: What can we learn from the empirical evidence on sticky costs? Working paper, Rice University and University of Michigan.

Balakrishnan, R., \& Gruca. T. (2008). Cost stickiness and core competency: A Note. Contemporary Accounting Research, 25, 993-1006.

Banker, R. D., \& Byzalov, D. (2014). Asymmetric cost behavior. Journal of Management Accounting Research, 26(2), 43-79.

Banker, R. D., Byzalov, D., Ciftci, M., \& Mashruwala, R. (2014). The moderating effect of prior sales changes on asymmetric cost behavior. Journal of Management Accounting Research, 26(2), 221-242.

Banker, R. D., Byzalov, D., \& Plehn-Dujowich, J. M. (2013). Demand uncertainty and cost behavior. The Accounting Review, 89(3), 839-865.

Bozkurt, O., Dokur, Ş., \& Yildirim, A. (2014). The Importance of Cost Calculation Method in the Accounting and Management of Turkish Operating Costs. A Research within the Scope of TAS-2. International Journal of Academic Research in Accounting, Finance and Management Sciences, 4(2), 38-46.

Brüggen, A., \& Zehnder, J. O. (2014). SG\&A cost stickiness and equity-based executive compensation: does empire building matter?. Journal of Management Control, 25(3-4), 169-192.

Calleja, K., Steliaros, M., \& Thomas, D. C. (2006). A note on cost stickiness: Some international comparisons. Management Accounting Research, 17(2), 127-140.

Chen, C. X., Gores, T., \& Nasev, J. (2013). Managerial overconfidence and cost stickiness. Retrieved from: http://ssrn.com/abstract $=2208622$.

Drury, C. (2012). Management and Cost Accounting, Eighth Edition. Thomson Learning.

Hair, J. F., Anderson, R. E., Babin, B. J., \& Black, W. C. (2010). Multivariate data analysis: A global perspective (Vol. 7). Upper Saddle River, NJ: Pearson.

Hansen, Don R., Mowen, M. M., \& Guan, L. Cost management: accounting \& control, 6th ed. Mason: South-Western, 2009.

Hansen, Don R., \& Mowen, M. M. (2015). Cornerstones of Cost Management, 3th ed. Mason, OH: Cengage Learning.

Hilton, R. W., Maher, M. W., Selto, F. H. (2008). Cost Management: Strategies for Business Decisions (4th ed.). New York: McGraw-Hill, Inc.

Nimocks, S. P., Rosiello, R. L., \& Wright, O. (2005). Managing overhead costs. McKinsey Quarterly, 41 (2), 106-117.

Noreen, E., \& Soderstrom, N. (1997). The accuracy of proportional cost models: evidence from hospital service departments. Review of accounting Studies, 2(1), 89-114.

Novák, P., \& Popesko, B. (2014). Cost variability and cost behaviour in manufacturing enterprises. Economics \& Sociology, 7(4), 89-103, 2014.

Okunbor, J. A. (2013). The application of cost behaviour and estimation in organisational decision making process. Journal of Research in National Development, 11(1), 217-227.

Oluwagbemiga, O. E., Olugbenga, O. M., \& Zaccheaus, S. A. (2014). Cost Management Practices and Firm's Performance of Manufacturing Organizations. International Journal of Economics and Finance, 6(6), 234.

Pichetkun, N., \& Panmanee, P. (2014). The Determinants of Sticky Cost Behavior: A Structural Equation Modeling Approach. Retrieved from: http://www.jap.tbs.tu.ac.th/files/Article/Jap23/Full/Jap23NuchPana.pdf (2015-10-21), 2014.

Popesko, B., \& Socova, V. (2016). Current trends in budgeting and planning: Czech survey initial results. International Advances in Economic Research, 22(1), 99-101.

Sharman, P. A. (2003). The case for management accounting. Strategic Finance, 85(4), 42-47.

Slavik, S., \& Bednár, R. (2014). Analysis of Business Models. Journal of competitiveness, 6(4), 19-40.

Uy, A. O. O. (2011). Modeling cost behavior: linear models for cost stickiness. Academy of Accounting and Financial Studies Journal, 15(1), 25-34. 
Uy, A. O. O. (2014). The dynamics of firm competitiveness: evidence from cost behavior of Filipino firms. Academy of Accounting and Financial Studies Journal, 18(4), 84-95.

Dalla Via, N., \& Perego, P. (2014). Sticky cost behaviour: evidence from small and medium sized companies. Accounting \& Finance, 54(3), 753-778.

Weiss, D. (2010). Cost behavior and analysts' earnings forecasts. The Accounting Review, 85(4), 1441-1471.

Yasukata, K. (2011). Are 'Sticky Costs' the Result of Deliberate Decision of Managers?. Retrieved from: http://ssrn.com/abstract=1444746. 